\title{
Pharmacodynamics Drug Interactions of Metformin with Aspirin and Nifedipine
}

\author{
Khidir A. M. Hassan ${ }^{1 *}$, Mahmoud M. E. Mudawi² and Mansour I. Sulaiman ${ }^{2}$ \\ 'Department of Pharmaceutics, Faculty of Pharmacy, Northern Border University, KSA; \\ khidiragab@yahoo.com \\ ${ }^{2}$ Department of Pharmacology and Toxicology, Faculty of Pharmacy, \\ Northern Border University, KSA
}

\begin{abstract}
Metformin is now being recognized as the standard therapy in T2D patients who are overweight. Metformin has many drug-disease interactions that can increase the risk of metformin-associated lactic acidosis. Therefore this study was conducted to evaluate any possible pharmacodynamic interactions between metformin and drugs used to treat chronic diseases e.g. Hypertension. The rats were fasted overnight before inducing diabetes with streptozotocin. The rats were given an intraperitoneal injection of streptozotocin (50 mg kg-1) freshly prepared in $0.1 \mathrm{M}$ sodium citrate buffer. The diabetic state was confirmed $72 \mathrm{~h}$ after streptozotocin injection. Diabetic rats were grouped into seven groups each group of five rats and distributed among the normal control group diabetic control group and the treatment groups. The treatment continued for 10 days. Blood samples were taken before treatment and after 10 days and analyzed for serum glucose, cholesterol, HDL, LDL, and triglycerides. In the diabetic control group which was given STZ alone the blood glucose level decreased significantly $(\mathrm{p}<0.05)$ after 10 days but still above the hyperglycemic level $(200 \mathrm{mg} / \mathrm{dl})$. The same was observed in the group treated with metformin. The group treated with nifedipine and aspirin showed significant reduction $(\mathrm{p}<0.01)$ in the glucose level below the hyperglycemic level $(200 \mathrm{mg} / \mathrm{dl})$. While the groups treated with (Metformin + Nifedipine) and (Metformin + Aspirin) showed highly significant reduction $(\mathrm{P}<0.001)$ in blood glucose level. These results conclude that the combination of (metformin + Nifedipine) and the combination of (Metformin + Aspirin) have highly significant hypoglycemic effect. It also showed that Nifedipine has promising role in reducing blood glucose level, lipid profile especially LDL-cholesterol, and body weight.
\end{abstract}

Keywords: Aspirin, Antidiabetic, Metformin, Nifedipine, Streptozotocin

\section{Introduction}

Diabetes mellitus $(\mathrm{DM})$ is a chronic metabolic disorder characterized by a hyperglycemia caused by insulin deficiency, often combined with insulin resistance. In diabetes, the homeostasis of carbohydrate and lipid metabolism is improperly regulated by the pancreatic hormone, insulin; resulting in an increased blood glucose level ${ }^{1}$.

Hyperglycemia occurs because of uncontrolled hepatic glucose output and reduced uptake of glucose by skeletal muscle with reduced glycogen synthesis. Diabetes mellitus is classified on the basis of the pathogenic process that leads to the hyperglycemia. The broad categories of DM are designated type 1 and type $2^{2}$.

Metformin lowers blood glucose concentration and improves insulin sensitivity by reducing hepatic gluconeogenesis and enhancing insulin-simulated peripheral glucose uptake. It also inhibits adipose tissue lipolysis, thereby reducing circulating levels of free fatty acids (FFA) $)^{3}$.

Metformin, an oral anti-diabetic drug, is being considered increasingly for treatment and prevention of cancer, obesity as well as for the extension of healthy life $\operatorname{span}^{4}$.

${ }^{*}$ Author for correspondence 
Metformin is not metabolised at all but is completely excreted in urine. Metformin may therefore accumulate and cause lactic acidosis if other medications have induced renal failure ${ }^{5}$.

When patients are diagnosed with diabetes, a large number of medications become appropriate therapy. These include medications for dyslipidemia, hypertension, antiplatelet therapy, and glycemic control which may lead to drug interactions with antidiabetic drugs ${ }^{6}$. Metformin has many drug-disease interactions that can increase the risk of metformin-associated lactic acidosis (MALA) ${ }^{6}$.

Drug interactions are often categorized as pharmacodynamic or pharmacokinetic in nature ${ }^{6}$. A pharmacodynamic drug interaction is related to the drug's effect on the body. Pharmacodynamic drug interactions can be either beneficial or detrimental to patients ${ }^{6}$.

Any drug that has the potential to raise blood glucose may produce apparent inefficacy of an oral hypoglycaemic drug. Stopping a drug which causes hyperglycaemia may produce a significant fall in blood glucose. This may require a parallel reduction in the dose of a hypoglycemic drug 5 .

Some drugs can lower blood glucose, but the mechanisms of action are not well understood. Taking one of these drugs with a hypoglycemic drug might cause clinically significant hypoglycaemia. The patient may need a lower dose or even have to cease the oral hypoglycemic drug. Conversely stopping a drug with the potential to lower blood glucose might produce relative inefficacy of a hypoglycemic drug and create a need for an increased dose $^{5}$.

\section{Justification of the Study}

It has been reported that diabetic patients may take other drugs to treat concomitant diseases. Diabetic patients may be administered antihypertensive drugs, NSAIDs, anti-ulcer drugs which may interact with metformin. Therefore this study was conducted to evaluate any possible pharmacodynamic interactions between metformin and drugs used to treat chronic diseases e.g. Hypertension

\section{Materials and Methods}

\subsection{Chemicals}

Streptozocin (Manufactured by Sigma- Aldrich, USA) was purchased from a local distributor in KSA, Sodium
Citrate (Manufactured by Lobel Chemie, laboratory reagents \& fine chemical, India) was availed from the laboratory stock at Northern Border University

Metformin (Glucophage 500 mg, Merck santé, France), Aspirin100 mg (Bayer, Germany) and Nifedipine (Adalat $20 \mathrm{mg}$, Bayer, Germany) were purchased from the local market.

\subsection{Method of Analysis}

Samples were analyzed for serum glucose, cholesterol, HDL, LDL, and triglycerides using the kits of Human Diagnostic Worldwide.

\subsection{Experimental Animals}

Wistar albino rats of either sex were used (Table 2) were obtained from the animal house at the faculty of pharmacy, Northern Border University. The animals were housed in a standard controlled animal care facility. The animals were maintained under standard nutritional and environmental conditions throughout the experiment and water was given ad libitum.

\subsection{Induction of Diabetes}

Rats were fasted overnight before inducing diabetes with streptozotocin. Streptozotocin is used to induce both type I and Type II diabetes based on the dose i.e. it is concentration dependent, for the induction of type I, $60 \mathrm{mg} / \mathrm{kg}$ is given intraperitoneally or intravenously, and for type II induction $40-50 \mathrm{mg} / \mathrm{kg}$ is the usual dose used ${ }^{1,7,8}$. In this study the rats were given an intraperitoneal injection of streptozotocin (50 mg kg-1) freshly prepared in $0.1 \mathrm{M}$ sodium citrate buffer. The diabetic state was confirmed 72 $\mathrm{h}$ after streptozotocin injection. Threshold value of fasting blood glucose was taken as $>200 \mathrm{mg} \mathrm{dL}-1^{8}$. Diabetic rats were weighed and matched for body weight and divided into following groups consisting five animals each:

- Group 1: Normal control

- Group 2: Diabetic Control

- Group 3: Diabetic rats administered Metformin 100 $\mathrm{mg} / \mathrm{kg}$ (10 days, p.o.).

- Group 4: Diabetic rats administered Aspirin $100 \mathrm{mg} /$ $\mathrm{kg}$ (10 days, p.o.).

- Group 5: Diabetic rats administered Nifedipine 20 $\mathrm{mg} / \mathrm{kg}$ (10 days, p.o.).

- Group 6: Diabetic rats administered Metformin $100 \mathrm{mg} /$ $\mathrm{kg}$ (10 days, p.o.) + Aspirin $100 \mathrm{mg} / \mathrm{kg}$ (10 days, p.o.). 
- Group 7: Diabetic rats administered Metformin 100 $\mathrm{mg} / \mathrm{kg}$ (10 days, p.o.) + Nifedippine $20 \mathrm{mg} / \mathrm{kg}(10$ days, p.o.).

\subsection{Blood Glucose Estimation}

Blood sample were collected from the retro orbital plexus of the rats and glucose was estimated before (day 0 ) and after treatment (day 10).

\subsection{Blood Lipids Estimation}

Blood samples were assessed for total cholesterol, HDL, LDL and triglycerides before (day 0 ) and after treatment (day 10).

\subsection{Body Weight Determination}

Weight of rats was recorded before and after the study period of 10 days.

\section{Results}

As shown in Table 1, a paired- samples t-test was conducted to compare the glucose level in rats with STZ induced hyperglycemia before treatment (time zero) and after 10 days. There was a highly significant difference $(p<0.001)$ in the groups treated with (Metformin + Nifedipine) and (Metformin + Aspirin).

Figure 1 compare the glucose level in rats with STZ induced hyperglycemia before treatment (time zero)

Table 1. Effect of drugs (Metformin, Aspirin, Nifedipine) on fasting blood glucose levels in STZ induced diabetes

\begin{tabular}{lccc}
\hline Group & Treatment & \multicolumn{2}{c}{ Blood Glucose $(\mathrm{mg} / \mathrm{dl})($ Mean \pm SEM $)$} \\
\cline { 3 - 4 } No. & $(\mathbf{n}=\mathbf{5})$ & Day 0 & Day 10 \\
\hline 1 & Diabetic control (STZ) & $394.60 \pm 44.35$ & $224.51 \pm 61.90 * \downarrow$ \\
2 & Metformin & $525.53 \pm 15.17$ & $312.09 \pm 43.81 * \downarrow$ \\
3 & Nifedipine & $269.60 \pm 34.76$ & $139.16 \pm 19.10 * \downarrow$ \\
4 & Metformin + Nifedipine & $555.80 \pm 6.89$ & $142.53 \pm 17.60 * * * \downarrow$ \\
5 & Aspirin & $229.30 \pm 40.08$ & $150.00 \pm 48.99 * \downarrow$ \\
6 & Metformin + Aspirin & $574.70 \pm 57.47$ & $197.28 \pm 53.41 * * * \downarrow$ \\
\hline$* \downarrow$ Significant decrease $(\mathrm{p}<0.05) * * * \downarrow$ & Highly significant decrease $(\mathrm{p}<0.001)$ (paired samples \\
T-test) compared Day 10 to Day 0. & \multicolumn{3}{l}{}
\end{tabular}

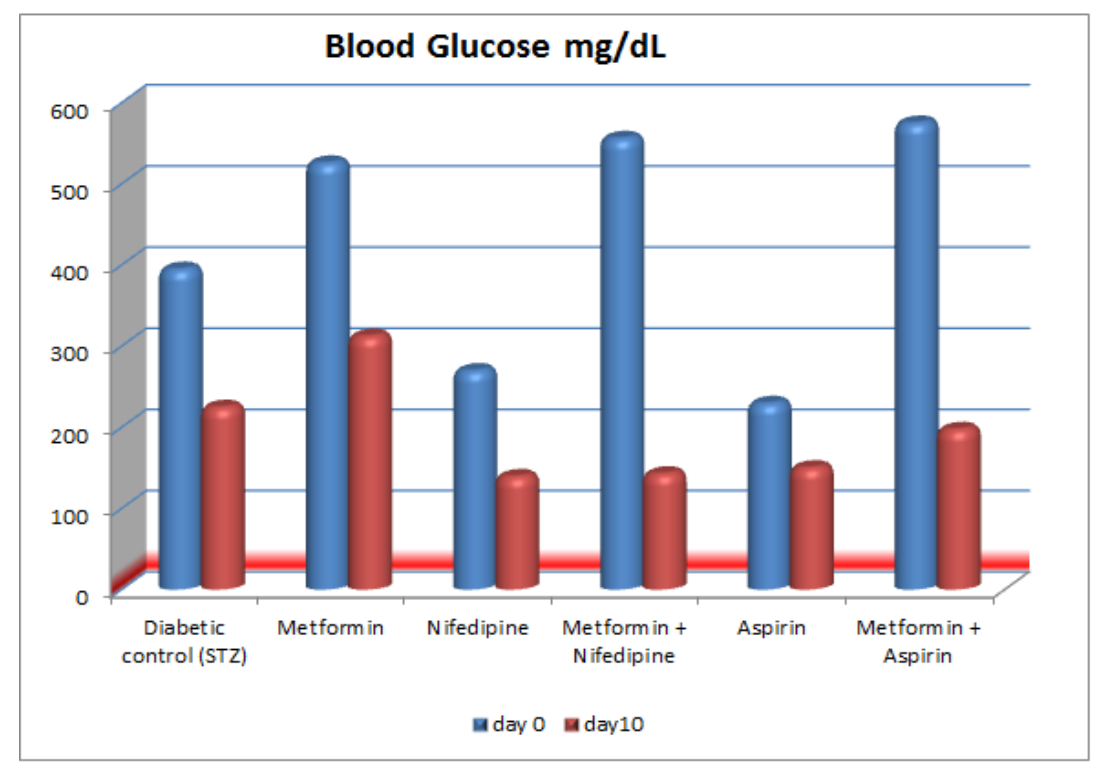

Figure 1. Effect of metformin, nifedipine and Aspirin on fasting glucose level. 
and after 10 days of treatment in different treatment groups.

Table 2 shows a paired- samples t-test was conducted to compare the body weight in rats with STZ induced hyperglycemia before treatment (time zero) and after 10 days. There was a highly significant reduction $(\mathrm{p}<0.001)$ in the group treated with Nifedipine.

Figure 2 show a comparison of body weight in rats with STZ induced hyperglycemia before treatment (time zero) and after 10 days of treatment in different treatment groups.

As shown in Table 3 a paired- samples t-test was conducted to compare the lipids level in rats with STZ induced hyperglycemia before treatment (time zero) and after 10 days. There was a highly significant reduction $(\mathrm{p}<0.001)$ in LDL - cholesterol concentration in the group treated with Nifedipine.

Figure 3 compare the lipid profile in rats with STZ induced hyperglycemia before treatment (time zero) and after 10 days of treatment in different treatment groups.

\section{Discussion}

The prevalence of diabetes is high among the Saudi population and represents a major clinical and public health problem $^{9,10}$ and many patients taking antidiabetic drugs

Table 2. Effect of Metformin, Aspirin, and Nifedipine on body weight in STZ induced diabetes

\begin{tabular}{lccc}
\hline \multirow{2}{*}{$\begin{array}{l}\text { Group } \\
\text { No. }\end{array}$} & Treatment & \multicolumn{2}{c}{ Body weight $(\mathrm{g})($ Mean \pm SEM $)$} \\
\cline { 2 - 4 } & $(\mathbf{n}=5)$ & Day 0 & Day 10 \\
\hline 1 & Diabetic control (STZ) & $176.00 \pm 11.99$ & $191.66 \pm 10.75 * \uparrow$ \\
3 & Metformin & $177.00 \pm 5.35$ & $178.50 \pm 6.84$ \\
4 & Nifedipine & $228.40 \pm 9.23$ & $192.00 \pm 8.79 * * * \downarrow$ \\
5 & Metformin + Nifedipine & $181.60 \pm 8.41$ & $184.50 \pm 9.08$ \\
6 & Aspirin & $195.40 \pm 13.11$ & $201.00 \pm 21.46$ \\
\hline$* \downarrow$ Significant decrease $(\mathrm{p}<0.05) * * * \downarrow$ Highly significant decrease $(\mathrm{p}<0.001)$ (paired \\
\multicolumn{2}{l}{ samples T-test) compared Day 10 to Day 0. }
\end{tabular}

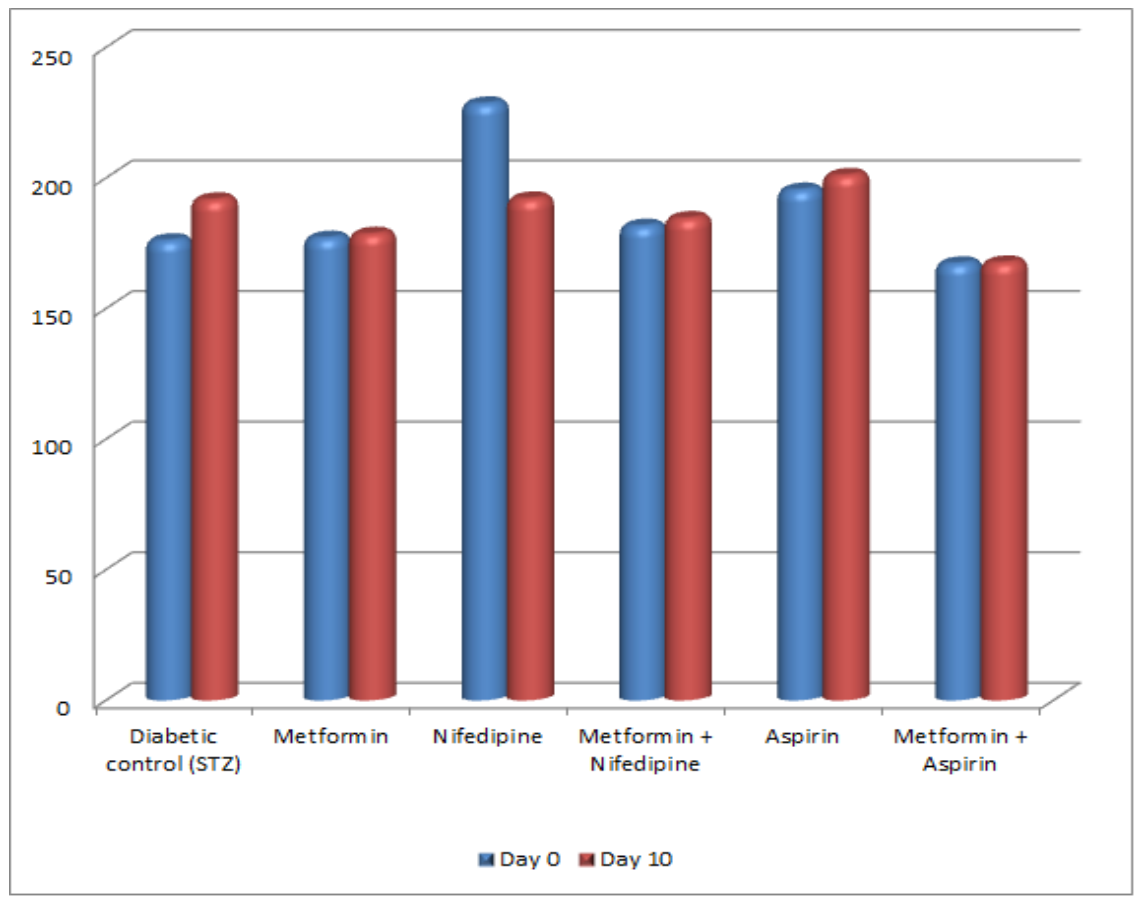

Figure 2. Effect of metformin, aspirin, and nifedipine on body weight. 
Table 3. Effect of Metformin, Aspirin, and Nifidipine on blood lipid levels in STZ induced diabetes

\begin{tabular}{|c|c|c|c|c|c|c|c|c|c|}
\hline \multirow[t]{2}{*}{$\begin{array}{l}\text { Group } \\
\text { No. }\end{array}$} & \multirow[t]{2}{*}{$\begin{array}{l}\text { Treatment } \\
(\mathrm{n}=5)\end{array}$} & \multicolumn{2}{|c|}{$\begin{array}{l}\text { Total Cholesterol (mg/ } \\
\text { dl) }(\text { Mean } \pm \text { SEM) }\end{array}$} & \multicolumn{2}{|c|}{$\begin{array}{c}\text { LDL }(\mathrm{mg} / \mathrm{dl}) \\
(\text { Mean } \pm \text { SEM })\end{array}$} & \multicolumn{2}{|c|}{$\begin{array}{c}\mathrm{HDL}(\mathrm{mg} / \mathrm{dl}) \\
(\text { Mean } \pm \text { SEM })\end{array}$} & \multicolumn{2}{|c|}{$\begin{array}{c}\mathrm{TG}(\mathrm{mg} / \mathrm{dl}) \\
(\text { Mean } \pm \text { SEM })\end{array}$} \\
\hline & & Day 0 & Day 10 & Day 0 & Day 10 & Day 0 & Day 10 & Day 0 & Day 10 \\
\hline 1 & $\begin{array}{l}\text { Diabetic control } \\
\text { (STZ) }\end{array}$ & $\begin{array}{c}62.63 \pm \\
7.08\end{array}$ & $\begin{array}{l}74.98 \pm \\
7.19 * \uparrow\end{array}$ & $\begin{array}{c}44.31 \pm \\
6.87\end{array}$ & $\begin{array}{l}12.72 \pm \\
4.50 * \downarrow\end{array}$ & $\begin{array}{c}178.98 \pm \\
62.56\end{array}$ & $\begin{array}{c}38.94 \pm \\
8.88\end{array}$ & $\begin{array}{c}103.84 \pm \\
24.06\end{array}$ & $\begin{array}{c}83.59 \pm \\
14.59\end{array}$ \\
\hline 2 & Metformin & $\begin{array}{c}68.69 \pm \\
6.70\end{array}$ & $\begin{array}{c}62.55 \pm \\
13.30\end{array}$ & $\begin{array}{l}52.64 \pm \\
4.13\end{array}$ & $\begin{array}{l}16.76 \pm \\
4.35 * \downarrow\end{array}$ & $\begin{array}{c}197.40 \pm \\
58.42\end{array}$ & $\begin{array}{l}31.52 \pm \\
6.07\end{array}$ & $\begin{array}{c}122.85 \pm \\
19.52\end{array}$ & $\begin{array}{c}155.99 \pm \\
64.54\end{array}$ \\
\hline 3 & Nifedipine & $\begin{array}{l}57.63 \pm \\
11.74\end{array}$ & $\begin{array}{c}46.84 \pm \\
5.32\end{array}$ & $\begin{array}{c}20.05 \pm \\
2.41\end{array}$ & $\begin{array}{c}11.73 \pm \\
2.22 * * * \downarrow\end{array}$ & $\begin{array}{c}27.85 \pm \\
5.23\end{array}$ & $\begin{array}{l}31.13 \pm \\
4.17\end{array}$ & $\begin{array}{c}194.02 \pm \\
71.29\end{array}$ & $\begin{array}{c}66.90 \pm \\
36.48\end{array}$ \\
\hline 4 & $\begin{array}{l}\text { Metformin + } \\
\text { Nifedipine }\end{array}$ & $\begin{array}{c}61.01 \pm \\
9.87\end{array}$ & $\begin{array}{l}48.20 \pm \\
5.65\end{array}$ & $\begin{array}{l}59.66 \pm \\
13.96\end{array}$ & $\begin{array}{l}6.80 \pm \\
1.48 * \downarrow\end{array}$ & $\begin{array}{l}137.62 \pm \\
33.24\end{array}$ & $\begin{array}{l}14.60 \pm \\
2.98 * \downarrow\end{array}$ & $\begin{array}{c}82.65 \pm \\
8.34\end{array}$ & $\begin{array}{l}35.93 \pm \\
4.65 * \downarrow\end{array}$ \\
\hline 5 & Aspirin & $\begin{array}{l}72.07 \pm \\
8.25\end{array}$ & $\begin{array}{l}87.11 \pm \\
23.17\end{array}$ & $\begin{array}{l}11.47 \pm \\
2.58\end{array}$ & $\begin{array}{c}7.23 \pm \\
3.55\end{array}$ & $\begin{array}{l}16.36 \pm \\
5.73\end{array}$ & $\begin{array}{l}29.10 \pm \\
7.76\end{array}$ & $\begin{array}{c}74.94 \pm \\
12.59\end{array}$ & $\begin{array}{c}32.90 \pm \\
11.03 * \downarrow\end{array}$ \\
\hline 6 & Metformin + Aspirin & $\begin{array}{c}63.03 \pm \\
3.81\end{array}$ & $\begin{array}{l}73.47 \pm \\
7.95\end{array}$ & $\begin{array}{c}144.32 \pm \\
88.68\end{array}$ & $\begin{array}{l}17.19 \pm \\
1.85\end{array}$ & $\begin{array}{c}223.34 \pm \\
80.63\end{array}$ & $\begin{array}{c}26.32 \pm \\
6.25\end{array}$ & $\begin{array}{c}88.74 \pm \\
28.66\end{array}$ & $\begin{array}{c}144.19 \pm \\
52.95\end{array}$ \\
\hline
\end{tabular}

$* \downarrow$ Significant decrease $(\mathrm{p}<0.05) * * * \downarrow$ Highly significant decrease $(\mathrm{p}<0.001)$ (paired samples T-test) compared Day 10 to Day 0.

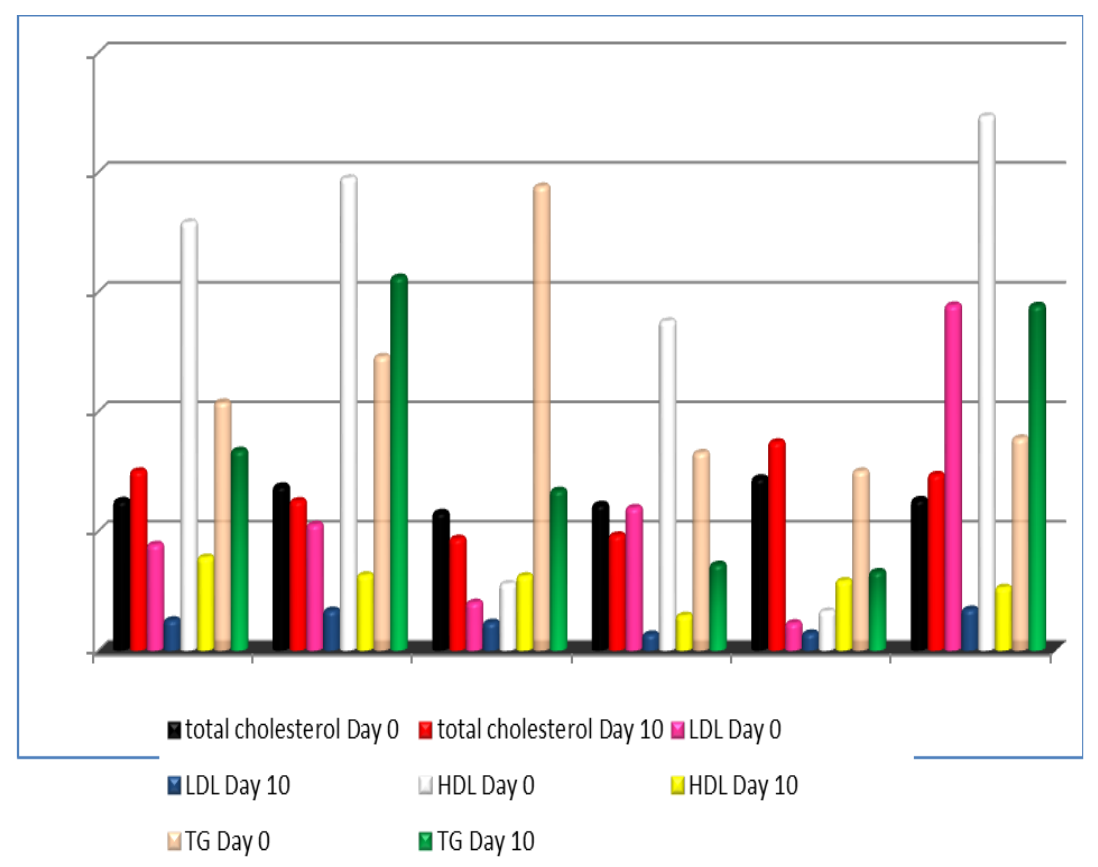

Figure 3. Effect of metformin, nifedipine and aspirin on blood lipid levels in STZ induced diabetes.

and antihypertensive drugs concomitantly which may lead to various drug-drug interactions. Therefore the main objective of this work was to study the pharmacodynamic interactions between metformin, nifedipine, and aspirin and their effects on blood glucose level, lipid profile and body weight.

In this study streptozocin (STZ) when administered intraperitoneally (IP) to rats the blood glucose level increased above $200 \mathrm{mg} / \mathrm{dl}$ within $48-72$ hours which considered hyperglycemic. In the diabetic control group which was given STZ alone the blood glucose level decreased significantly $(\mathrm{p}<0.05)$ after 10 days but still above the hyperglycemic level (200mg/ dl). The same was observed in the group treated with metformin. On the other hand the group treated with nifedipine and aspirin showed significant reduction ( $p$ 
$<0.01)$ in the glucose level below the hyperglycemic level $(200 \mathrm{mg} / \mathrm{dl})$.

Interestingly, the groups treated with (Metformin + Nifedipine) and (Metformin +Aspirin) showed highly significant reduction $(\mathrm{P}<0.001)$ in blood glucose level. Taking one of these drugs with a hypoglycemic drug might cause clinically significant hypoglycaemia. The patient may need a lower dose or even have to cease the oral hypoglycemic drug. Conversely stopping a drug with the potential to lower blood glucose might produce relative inefficacy of a hypoglycemic drug and create a need for an increased dose $e^{5}$. Therefore patients taking metformin with nifedipine or aspirin need close monitoring for blood glucose level.

Suresha et al. reported that Nifedipine worsens glycemic control in normal rats after glucose challenge through inhibition of basal insulin secretion ${ }^{11}$. Jobran $\mathrm{Al}$ Qahtani et al. also reported that Nifedipine has induced hyperglycemia in an infant ${ }^{12}$. These results does not go on line with our finding regarding the effect of Nifedipine, in which Nifedipine has reduced blood glucose level in STZ induced hyperglycemia in rats. However, our finding agreed with the finding of Kaymaz et al. who concluded that calcium channel blockers (Nifedipine) have beneficial effects on body weight, glycated hemoglobin and blood glucose level ${ }^{13}$. Choi and Lee reported that the combination of nifedipine and metformin caused reduction in blood glucose level which may be due to the fact that both metformin and nifedipine are commonly metabolized via hepatic CYP2C and 3A subfamilies in rats. Therefore; simultaneous administration of both drugs may lead to an increase of the bioavailability of both drugs due to competitive inhibition for the metabolism of nifedipine and metformin by each other via intestinal CYP3A1/2 in addition to competitive inhibition for hepatic metabolism of each drug ${ }^{14}$.

In a study performed to investigate the beneficial effects of nifedipine on abnormalities of platelets and lipid metabolism in patients with type II diabetes mellitus, it was found nifedipine produced significant reduction of lipid profiles except for HDL which showed significant increase ${ }^{15}$. This result agrees with our findings which demonstrated that nifedipine produced highly significant reduction in LDL-cholesterol blood level in rats.

Many studies documented that Aspirin can significantly decrease blood glucose level ${ }^{16}$ which is in agree with our findings in this study. It is claimed that Aspirin can cause decrease in basal rates of hepatic glucose production, enhances tissue insulin sensitivity, decreases insulin clearance, and decreases oxidative stress in diabetic patients ${ }^{17,18}$.

In this study Nifedipine produced highly significant reduction $(\mathrm{P}>0.001)$ in body weight in the rats with STZ induced hyperglycemia. In addition Nifedipine showed highly significant $(\mathrm{P}<0.001)$ decrease in LDL-cholesterol concentration compared to day zero for the same group; While Aspirin produced significant $(\mathrm{p}<0.05)$ reduction in triglycerides (TG) concentration.

\section{Conclusion}

From this study we conclude that the combination of (metformin + Nifedipine) and the combination of (Metformin + Aspirin) have highly significant antidiabetic effect which might be helpful for diabetic patients with concomitant hypertension. Our study showed that Nifedipine has promising role in reducing blood glucose level, lipid profile especially LDL-cholesterol, and body weight.

\section{Acknowledgement}

The authors would like to thanks, the deanship of scientific research, at Northern Border University, for their financing the project, and for their full support at all research stages.

\section{Conflict of Interest}

None to declare

\section{References}

1. Poonam T, Prakash PG, Kumar VL. Interaction of momordica charantia with metformin in diabetic rats. American Journal of Pharmacology and Toxicology. 2013; 8(3):102-6.

2. Undale VR, Bhosale AV, Upasani CD. Study of Pharmacodynamic Interaction between a Polyherbal Formulation BSL-150 and Metformin. Pharmaceutical Crops. 2014; 5(Suppl 1: M6):67-76.

3. Chetan DBG, Bhat KM, Shivprakash. Estimation and pharmacokinetics of metformin in human volunteers. Indian J Pharm Educ Res. 2007; 41(2). 
4. Berstein LM. Metformin in obesity, cancer and aging: addressing controversies. Aging (Albany NY). 2012 May; 4(5):320-9.

5. Shenfield GM. Drug interactions with oral hypoglycaemic drugs. Australian Prescriber 2001; 24(4).

6. Triplitt C. Drug Interactions of Medications Commonly Used in Diabetes. Diabetes Spectrum. 2006; 19:4(4):202-11.

7. Erdal N, Gurgul S, Kavak S, Yildiz A, Emre M. Deterioration of bone quality by streptozotocin (STZ)- induced type 2 diabetes mellitus in rats. Biological trace element research. 2011 June 01; 140(3):342-53.

8. Akbarzadeh A, Norouzian D, Mehrabi MR, Jamshidi Sh, et al. Induction of diabetes by streptozotocin in rats. Indiain Journal of Clinical Biochemistry. 2007; 22(2):60-4.

9. Alqurashi KA, Aljabri KS, Bokhari SA. Prevalence of diabetes mellitus in a Saudi community. Ann Saudi Med. 2011 Jan-Feb; 311:19-23.

10. Madani KA. Obesity in Saudi Arabia. Bhrain Med Bull. 2000; 22(3).

11. Kanatsuna T, Nakano K, Mori H, Kano Y, et al. Effects of nifedipine on insulin secretion and glucose metabolism in rats and in hypertensive type 2 (non-insulin dependent) diabetics. Arzneimittelforschung. 1985; 35(2):514-7.

12. Al Qahtani J, Al Harthi A, Fatinni Y, Al Bakri A, Al-Fifi S, Asindi AA, Al Daama S. Nifedipine-induced Hyperglycaemia in an infant: A case report. Nigerian Journal of Paediatrics. 2001; 28(1):18-20.
13. Kaymaz AA, Tan H, Buyukdevrim AS. The effects of calcium channel blockers, Verapamil, Nifedipine and Diltiazem, on metabolic control in diabetic rats. Diabetes Res Clin Pract. 1995 Jun; 28(3):201-5.

14. Choi YH, Lee MG. Pharmacokinetic and pharmacodynamics interaction between nifedipine and metformin in rats: competitive inhibition for metabolism of nifedipine and metformin by each other via CYP isozymes. Xenobiotica. 2012 May; 42(5):483-95.

15. El-Sayed EE, Abdel-Sater KA. Beneficial Effects of Calcium Channel Blocker "Nifedipine" on Abnormalities of Platelets and Lipid Metabolism in Patients with Type II Diabetes Mellitus. J Diabetes Metab. 2011; 2:131. doi:10.4172/21556156.1000131.

16. Coe LM, Denison JD, McCabe LR. Low Dose Aspirin Therapy Decreases Blood Glucose Levels but Does not Prevent Type I Diabetes-induced Bone Loss. Cell Physiol Biochem. 2011; 28:923-32.

17. Hammadi SH, AL-Ghamdi SS, Yassien AI, AL-Hassani SD. Aspirin and Blood Glucose and Insulin Resistance. Open Journal of Endocrine and Metabolic Diseases. 2012; 2:1626.

18. Amiri L, John A, Shafarin J, Adeghate E, et al. Enhanced Glucose Tolerance and Pancreatic Beta Cell Function by Low Dose Aspirin in Hyperglycemic Insulin Resistant Type 2 DiabeticGoto-Kakizaki(GK)Rats.CellPhysiolBiochem.2015; 36:1939-50. 